\title{
Thyroid Dysgenesis
}

National Cancer Institute

\section{Source}

National Cancer Institute. Thyroid Dysgenesis. NCl Thesaurus. Code C85190.

A congenital condition characterized by hypoplasia, absence, or ectopic position of the thyroid gland. It is manifested with congenital hypoparathyroidism. 